\title{
EXPERIENCIAS DE ARMARIO: UNA LECTURA QUEER DE DOS DRAMAS DE LUIS ALBERTO HEIREMANS
}

\author{
Andrés Kalawski \\ Pontificia Universidad Católica de Chile \\ Santiago, Chile \\ akalawsk@uc.cl \\ Daniel Party \\ Pontificia Universidad Católica de Chile \\ Santiago, Chile \\ dparty@uc.cl \\ Cristián Opazo \\ Pontificia Universidad Católica de Chile \\ Santiago, Chile \\ cmopazo@uc.cl
}

\section{RESUMEN / ABSTRACT}

Pese a su vigencia, la dramaturgia de Luis Alberto Heiremans (1928-1964) sigue siendo leída de acuerdo con las claves del existencialismo cristiano y el simbolismo que abrazaron los teatros universitarios chilenos en sus tres primeras décadas (1941-1973). La crítica especializada ha desatendido las claves homoeróticas que ofrecen las piezas más divulgadas del autor, ignorando las numerosas marcas textuales que insinúan afectos homosexuales.

En este artículo, ensayamos una lectura queer de Moscas sobre el mármol (1958) y Arpeggione, la tercera parte de Buenaventura (1962), textos estrenados fuera de Chile y ausentes de nuestras carteleras por varias décadas. A través de esta lectura explicamos cómo la dramaturgia de Heiremans problematiza el desafío de mencionar afectos, entonces, penados por ley: ya sea a través de citas literarias fallidas (Moscas sobre el mármol) o mediante referencias musicales (Arpeggione). Estas obras muestran las transformaciones de las posibilidades de una vida queer en un estado con afán higiénico de modernidad. Su revisión abre nuevas posibilidades estéticas y de comprensión de la historia del teatro chileno.

Palabras clave: Teatro chileno, historia y crítica, dramaturgos chilenos, Luis Alberto Heiremans, estudios queer. 


\section{CLOSET EXPERIENCES: A QUEER READING OF TWO PLAYS BY LUIS ALBERTO HEIREMANS}

Despite its currency, the dramaturgy of Luis Alberto Heiremans (1928-1964) continues to be read through the lens of Christian existentialism and symbolism, two qualities espoused by Chilean university theatres during their first three decades of existence (1941-1973). Critics have overlooked the homoerotic elements present in Heiremans 'best-known works, effectively ignoring multiple textual markers that suggest homosexual affections.

We propose a queer reading of Moscas sobre el mármol (1958) and Arpeggione, the third part of Buenaventura (1962), texts that premiered outside of Chile and that were not included in our programming for decades. Through this lens we explain the ways in which Heiremans' dramaturgy problematizes the challenge of mentioning affects, then criminalized: in one case through failed literary allusions (Moscas sobre el mármol), in the other through the use of musical references (Arpeggione). These works show how the possibilities of queer life were transformed under a state invested in a sanitized version of modernity. This revision opens new aesthetic possibilities and new understandings of Chilean theatre history.

KEYWORDS: Chilean theatre, history and criticism, Chilean playwrights, Luis Alberto Heiremans, Queer studies.

Recepción: 14/04/2020

Aprobación: 24/01/2021

\section{INTRODUCCIÓN}

"[L.A. Heiremans] Desea conocer, experimentar, ser testigo o actor, de cada posibilidad de ser realmente un hombre"

HERNÁN DEL SOLAR

"Vámonos a otros roperos / a llenarlos de agujeros..."

María Elena WaLsh

En este ensayo, que entrelaza tres voces, nos proponemos releer dos dramas de Luis Alberto Heiremans (Santiago, 1928-1964) desde los repertorios queer ${ }^{1}$ que ellos llevan inscritos: Moscas sobre el mármol (1958) y

1 En este texto, empleamos la voz queer, en inglés, por dos razones: por un lado, para declarar la deuda intelectual con el trabajo de Eve Kosofsky Sedgwick y, por otro, para hacer un guiño al cosmopolitismo lingüístico del propio Heiremans, que alternaba con naturalidad entre el francés, el inglés y el castellano. No olvidemos que en la tradición queer chilena, de 
Arpeggione (1962). Con el rótulo de "repertorios queer" designamos esas tramas de marcas textuales cuyas connotaciones participan de la semántica clandestina que las comunidades homosexuales van cristalizando en su afán por significar "el amor que no osa decir su nombre" bajo las condiciones de censura y represión que cada época les impone. Basta una rápida hojeada a los dramas más celebrados de Heiremans para que el lector "entendido" comience a notar la recurrencia de pistas queer. Piénsese, sin ir demasiado lejos, en los ejemplos más evidentes, pero jamás estudiados: Enrique y Julián, los adolescentes afectados de Moscas sobre el mármol (1958) que sellan su complicidad con un pacto de sangre. O en Barón y Barahona, los malabaristas andróginos de El tony chico (1964), que "visten igual[es]", "se lanzan anillos de colores" y parecen flotar en secreto "equilibrio" (391-98).

Curiosamente, pese a la ingente exuberancia con la que estos repertorios invisten las acotaciones y los diálogos de la dramaturgia de Heiremans, la crítica los ha ignorado. De hecho, nada se comenta de ellos en los dos volúmenes que, con la llegada del nuevo milenio, apuestan por reivindicar la vigencia de la escritura escénica de Heiremas: Teatro completo (2002), de Norma Alcamán, y Colección ensayos críticos (2012), compilado por Carola Oyarzún y Cristián Opazo. ¿Qué significa este silencio crítico? O, como diría Eve Kosofsky Sedgwick, ¿por qué, a veces, nos reusamos a nombrar lo obvio? Estas son las preguntas que guían este ensayo. Asimismo, de la mano de la misma crítica estadounidense, encontramos la máxima que ampara nuestra lectura: el afán de una aproximación crítica queer es hacer que un texto que se arriesga a exhibir su diferencia obtenga una respuesta distinta del silencio por parte de quien lo ausculta. Con reciprocidad, debemos tener la "osadía" de "arriesgar[nos]" a apuntar "lo evidente" para, así, corresponder el gesto aventurado de quien cifró el texto que leemos (Kosofsky Sedgwick 35). Cuando investigamos teatro, la escritura crítica tiene la oportunidad de poner en escena -y con ello restituir- aquello que el medio teatral, en otro momento, prefirió extraviar en los armarios de los bastidores.

Para demostrar cómo funciona esta cuidada retórica de los afectos proscritos, dividiremos nuestro trabajo en tres secciones. En la primera, abordaremos Moscas sobre el mármol. De manera deliberada, leeremos

Donoso a Fuguet, el extranjerismo es, a fin de cuentas, un léxico que permite expresar afectos proscritos. 
un conjunto de chistes, gestos, miradas, murmullos, poses y susurros, ya no como símbolos de trascendencia, sino como una jerga que -como en el cruising callejero- interpela a una comunidad indeciblemente queer de contemporáneos (p. ej. Adolfo Couve, José Donoso, Luis Oyarzún, Mauricio Wacquez). En consecuencia, la primera parte revelará una manera de "administrar la lengua". La segunda parte, en tanto, ofrece "una lectura cerrada" de Arpeggione. A la fecha, los críticos teatrales han observado que el arpeggione -instrumento musical-cumple un rol simbólico ya que, como invención romántica olvidada, señalaría la obsolescencia de un tipo de artista incapaz de seguir el ritmo de la modernidad. Sin embargo, esos críticos no han considerado más detenidamente las claves de género que conlleva la cita a este objeto extraviado. Por ende, resta dilucidar el sentido de la cadena léxica que desarrolla la dramaturgia, estableciendo relaciones de contigüidad metonímica entre el instrumento, las sonatas y la biografía de Schubert -texto cultural y musical que, en las últimas décadas, también se ha revelado como queer-.

En la tercera parte, en tanto, nos detendremos en un aspecto que ronda las condiciones de producción y circulación de Moscas sobre el mármol y Arpeggione: en vida, Heiremans no las escenificó en Chile (hay pistas de versiones menores que llegaron a las tablas en Alemania, sin demasiada repercusión). En lugar de contentarnos con el supuesto de que el "ocultamiento" de estas piezas sea un mero efecto de la censura homofóbica, creemos que es posible comprender este destino común como seña de una calculada "economía" escénica maquinada por el propio Heiremans. ¿Cuál es la agencia del dramaturgo en la manipulación de su propio archivo? Para nosotros, antes que ser un prestidigitador de símbolos, Heiremans es un agudo administrador de un archivo que, a veces, sirve de biblioteca erudita y, otras tantas, de armario. Eso sí, antes de emprender nuestra lectura, sirva ofrecer una contextualización doble: primero, de la escena dentro de la que ha sido leída la obra de Heiremans y, enseguida, de la intrincada biografía cultural del dramaturgo.

\section{LA LUZ DEL SOL}


Para el teatro chileno, la generación de dramaturgos del $50^{2}$ sigue siendo un sol: a la vez, ilumina y encandila. Ilumina por la brillantez de los textos que nos lega, por la vigencia de este acervo, por el estatuto de maestros que se les concede a sus autores y la popularidad de sus obras más señeras: mientras la última reposición de La pérgola de las flores (1958) de Isidora Aguirre (1919-2011) repletó la Sala 1 del GAM en pleno estallido social de octubre de 2019, La remolienda (1965), de Alejandro Sieveking (1934-2020) no cesa de leerse y montarse en colegios y escuelas de Teatro. Así, en el ámbito del teatro, el peso de esta generación aún aplasta las ramas de nuestros árboles genealógicos: la monumentalidad conferida a sus dramaturgias y la mitificación de los llamados teatros universitarios, muchas veces, impide comprenderlas desde perspectivas "menores" (Guattari y Deleuze 16). Por lo mismo, cuando se escribe sobre estos dramaturgos, aún priman epítetos que, si no los disciplinan como exponentes criollos de vanguardias metropolitanas, los alejan de sus devenires políticos o sexuales.

Para evitar encandilarnos no es necesario voltear la mirada, ni mucho menos derribar aquella generación: "miramos al sol a través de un cristal ahumado; deberíamos mirar hacia el pasado a través de cristales de colores" (Barnes 114). Quizás baste con cambiar el color del cristal con el que miramos ese pasado, pues, la manera en que observamos a la generación de dramaturgos que nos ocupa no puede disociarse de los cambios institucionales políticos que se suceden en sus años de formación (décadas de 1940 y 1950) e instalación en el campo cultural (década de 1960). Institucionalmente -debe tenerse en cuenta-, los dramaturgos de la generación de 1950 son los agentes de la "nacionalización del teatro" que propician las universidades en la década de $1940^{3}$. Aguirre, Díaz o Heiremans ingresan a la Universidad de Chile y

\footnotetext{
Bautizada así por el escritor Enrique Lafourcade, quien con ese rótulo refiere a sus contemporáneos. Mientras la narrativa ubica allí a José Donoso o Jorge Edwards, la dramaturgia reconoce a Isidora Aguirre, Fernando Debesa, Jorge Díaz, María Asunción Requena, Alejandro Sieveking y Egon Wolff, además del propio Heiremans. Desde la crítica académica, Cedomil Goic la define como la generación de 1957. Ambos-Goic y Lafourcade-coinciden en que el rasgo mínimo distintivo de las obras de estos autores es el escepticismo frente a las formas de convivencia sobre las que se yergue la sociedad chilena (Goic 33).

El Estado nacionalizó el teatro chileno a través de su apoyo a compañías universitarias que hicieron de las prácticas escénicas una efectiva herramienta de educación cívica en los días del Frente Popular. Téngase presente que, en 1941, los estudiantes de Pedagogía en Castellano de la Universidad de Chile fundan un Teatro Estudiantil que, meses después,
} 
la Universidad Católica a cursar estudios de Trabajo Social, Arquitectura y Medicina, respectivamente. Pero, a medio camino, renuncian a sus profesiones para plegarse a la nóveles compañías universitarias. Desde ahí, son ellos quienes fabulan las ficciones escénicas que, desde sus miradas de élite - burguesía ilustrada, colonias europeas-imaginan nuevas cartografías para un Chile que se reinventa junto con su teatro.

Efectivamente, la misma monumentalidad de la historia que nuestros dramaturgos ayudan a escribir puede terminar por caerles encima hasta el punto de asfixiarlos. Los teatros universitarios, al ocupar un espacio hegemónico de producción y formación artística, mantienen también el control institucional de la interpretación. Su manera de recrear la tradición afecta directamente la interpretación que los intelectuales hacen de ella. No se trata de que la academia no haya producido análisis fértiles, dinámicos y tensionados, sino de que lo han hecho dentro de un marco institucional que deja poco espacio (Kalawski 113-14).

De acuerdo con esta alegoría lumínica, huelga decir que Luis Alberto Heiremans fue una de las luces más brillantes de su generación. Formado como médico, y a pesar de su muerte muy temprana debido a un cáncer linfático, desarrolló una carrera relevante y prolífica como dramaturgo, además de trabajar como traductor, actor y profesor de la Escuela de Arte dramático de la Universidad Católica. En paralelo, publicó numerosos cuentos y una novela: Puerta de salida (1964), de sugerente título y fecha de publicación. A diferencia de otros miembros de su generación, un amplio abanico de su obra se sigue representando en Chile. Solo en la última década, ha habido varios montajes que han concitado éxitos de público y crítica en distintos circuitos del teatro profesional: en 2010, Moscas sobre el mármol (seleccionada por el Festival Santiago a Mil como una de las piezas claves del siglo XX chileno, bajo la dirección de Alejandro Castillo); en 2012, El año repetido (estrenada en teatro Sidarte en clave "realismo sucio" por Antonio Campos); en 2013, Versos de ciego (recuperada por el Teatro UC en su aniversario 70 como un clásico de su primer repertorio) y El mar en la muralla (segunda entrega de la revisión emprendida por el mencionado Campos); y, en 2017, Arpeggione (dirigida por Jesús Urqueta, seleccionada en el Festival Santiago a Mil y galardonada

deviene Instituto de Teatro. Y, con idéntico afán, también los estudiantes con vocación de cartógrafos fundan teatros-escuelas en la Universidad Católica (17 de octubre de 1943) y la Universidad de Concepción (19 de noviembre de 1945). 
por el Círculo de Críticos de Arte). Y, todo esto, sin contar que su drama El abanderado, además de reeditarse con singular periodicidad, fue incluido en el libro Antología: un siglo de dramaturgia chilena (proyecto Bicentenario que, en 2010, ofreció una selección de lo que un comité de críticos académicos estableció como el canon nacional $)^{4}$.

La atención que creadores, críticos, espectadores y lectores han prodigado a la producción dramática de Luis Alberto Heiremans no ha ido de la mano con lecturas que quiebren el cristal ahumado que lo sitúa, casi siempre, como un epígono criollo del existencialismo cristiano de Gabriel Marcel: ascético, alegórico, cristiano, existencialista y lírico son los epítetos que se repiten en sus obituarios ${ }^{5}$. Este léxico consensuado que personifica a Heiremans como un prestidigitador de símbolos suscita un efecto paradójico en la retórica de los críticos que con mayor creatividad y rigor han rescatado y analizado su dramaturgia: mientras crece el consenso en la selección de epítetos que se le prodigan al autor, más incierta o inaprensible se les hace su obra. Parece que siempre se les escapara algo. Considérense algunos ejemplos.

Explorando su dramaturgia inicial, Carola Oyarzún detecta la recurrencia de una oscuridad, retórica y argumental, que codifica como lo "misterioso" y lo "nocturno" (18). La mayoría de los personajes protagónicos de los dramas de Heiremans manifiestan un desasosiego estructural que podemos considerar como expresión genuina de un afán por "restituir a la experiencia humana su peso ontológico" (36). Ese peso ontológico se hace palpable en la "percepción de que más allá de nuestra inmediatez, hay un mundo otro al que acceder" (21). Ese mundo "otro", donde la gravedad no ata a los personajes, emerge en "la noche", que es "la encargada de generar el misterio y favorecer la búsqueda de experiencias conducentes al ser profundo de los personajes" (ibid.). En la

$4 \quad$ El archivo de Heiremans esconde una trama de relaciones que todavía reclaman debido análisis. Por ejemplo, El abanderado es un espectro que ronda, mediante citas y alusiones El chacal de Nahueltoro (1969), el clásico del cine chileno de Miguel Littin. La fascinación de Littin con el texto de Heiremans quizá obedezca a que el entonces joven cineasta tuvo un pequeño papel como actor en el estreno de El abanderado (Instituto de Teatro de la Universidad de Chile, dirección de Eugenio Guzmán, 1962).

Considérense los tres títulos claves que determinan su recepción crítica: Temas y símbolos en la obra de Luis Alberto Heiremans (1970) de Teresa Cajiao Salas, La poética teatral de Luis Alberto Heiremans (1992) de Eduardo Thomas, y Heiremans (2012), compilado por Carola Oyarzún y Cristián Opazo. 
noche, y solo en la noche, estos cuerpos se permiten "vivencias más auténticas y libres" (ibid.).

A falta de una noche que los libere, los personajes de Heiremans - muchas veces encerrados en paisajes mediterráneos- se inventan juegos, vicarias experiencias de consuelo. Esas series de juegos sin fin son -a decir de Eduardo Thomas- las prácticas sostenedoras de una teatralidad que, a través de sus símbolos, permite aprehender el sistema de pensamiento y lenguaje del dramaturgo ("Función" 112). Ahora bien, los personajes intentan suplir la liberación nocturna que no alcanzan a través de juegos - juegan porque no pueden decir ni ser-. Sin embargo, estos juegos se tornan angustiosos porque hay algo que tampoco consiguen representar: "[p]or medio de lo lúdico, los personajes abren espacios en los que se ficcionalizan ellos mismos como sujetos y sus deseos. El orden imaginario posibilita la relación abierta entre los protagonistas" (Thomas, "Función" 139).

Con todo, quizá "juego" sea una mala palabra, porque el juego supone el ocio y el goce y aquí se trata de estrategias de supervivencia, de necesidad, de respuesta a un silencio impuesto. La realidad no permite una relación abierta que los personajes claman por tener. Aquí es una estrategia fallida: "los personajes se unen creativamente en el juego durante un lapso limitado y se frustran al imponerse finalmente la realidad mediocre sobre la ficción representativa de los deseos" (Thomas, "Función" 113). La crítica ha sido aguda en mostrar el desasosiego que puebla la obra de Heiremans, pero se ha negado a sacarlo de ese nicho incómodo de autor hierático y místico. No se nombra el deseo que se pone en juego, no se nombra lo nocturno que la noche libera.

¿De qué manera una lectura en clave queer puede ayudar a liberarlos de este peso y, sobre todo, puede contribuir a comprender las cavilaciones cotidianas que los rondan en días donde solo parece caber el heroísmo? ${ }^{6}$ Esta es la pregunta que este trabajo intenta responder a partir de la revisión de dos dramas de Luis Alberto Heiremans, Moscas sobre el mármol (1958) y Arpeggione (1962).

\section{MAGNOLIAS RARAS}

El manuscrito de Moscas sobre el mármol está datado en 1958, una época "rara". Si se mira la trayectoria de Heiremans, se observará que antes de

\footnotetext{
"Peso" y "asfixia" no son metáforas triviales cunado queremos pensar historias de vida queer. En Chile, la homosexualidad estuvo penada por ley hasta el 12 de julio de 1999.
} 
1958 escribe sus textos de formación (comedias fallidas y auto sacramentales que parecen borradores inconclusos). Después de 1958, en tanto, asoma su trilogía canónica: Versos de ciego (1960), El abanderado (1962) y El tony chico (1964), todas estrenadas y, hasta el día de hoy, vigentes. Como se ve, Moscas sobre el mármol queda a medio camino o, en el mejor de los casos, como una obra bisagra. La trama es una ambigua historia de amor y celos entre dos amigos, Julián y Enrique, cuyos afectos están flanqueados por la crisis del latifundio y las presencias castradoras de la madre sobreprotectora y la esposa beata de uno de ellos (Julián). La obra tiene un pie en el melodrama y otro en el realismo sicológico de Tennessee Williams. La acción se inicia cuando Julián -quien vive en un fundo arruinado con su madre y esposarecibe a un amigo de infancia, Enrique. Excéntrico, como un epígono de Darío, Julián idea un juego para recibir a su amigo. Le propone cazar a un fantasma, que es un peón disfrazado, pero termina sorprendido por otro fantasma: el de los celos que le provoca la cercanía de su mujer y su amigo. El juego, naturalmente, sale mal.

La capilla abandonada del fundo que contiene la acción da cuenta de la ambigüedad del texto respecto de la tradición: se puede ser a la vez iconoclasta y reverencial. La obra, como bien ha observado la crítica, instala en un mundo rural a personajes sumamente urbanos (Fernández 113), en una tensión que no se aprovecha teatralmente. De hecho, la obra se estrenó en Chile recién en 1994, treinta años tras la muerte del autor, bajo la dirección de Alejandro Castillo y las actuaciones de Luciano Cruz-Coke y Francisco Pérez-Bannen. Sobre la textura homoerótica de la dramaturgia, la crítica no se pronuncia.

A nosotros, Moscas sobre el mármol nos seduce porque, justo con ella, el cuerpo entra en la escena: ¿qué pasará con las economías del deseo cuando el espolón del ferrocarril penetre los valles del Aconcagua o de Colchagua?, ¿qué destrezas supone el cruising citadino?, ¿qué prácticas sexuales modifica la ya inevitable intermediación del dinero?, se pregunta Heiremans. Porque, entonces, "yo me sentía seguro en aquellos días melancólicamente alegres de Santa Cruz", escribe Luis Oyarzún, en su Epistolario familiar (53). En Valparaíso o Santiago, testimonian los contemporáneos del dramaturgo, había una "masonería de invertidos" que, en sus "cacerías", distinguía a los "pupilos" entendidos de los "rotos" mostaceros, “¿sería verdad?, ¿sería mentira?", cavila Joaquín Edwards Bello (162). Las respuestas están penadas por ley. El propio Heiremans sugiere una, pero se niega a estrenarla en vida: Moscas sobre el mármol. 
En esta atmósfera de "erotismo y represión" - como diría Sarlo (69)-, el juego que propone Julián parece una estrategia desesperada para debatir en torno a un pacto de sangre - no de palabras- que ha sido violado:

JULIÁN: [...] Porque entre nosotros no había secretos. ¿Te acuerdas? Ninguno. Ni en el colegio ni después... Esa tarde que nos abrimos las venas y mezclamos las sangres juramos no tenerlos nunca. ¿Te acuerdas de esa tarde? No apareciste en el colegio y yo sufrí hasta la última campana, pensando que tal vez no te vería nunca más. Corrí a tu casa y al verte ahí, en tu cama, enfermo, enfermo, pero no muerto, sentí un inmenso alivio. Y fue entonces cuando te obligué a cortarte la muñeca con la misma hoja con la que habías estado sacándole punta a los lápices de colores y ¡mira! Yo todavía conservo la cicatriz... ¿ Y tú? (Le agarra la muñeca. Enrique instintivamente retira su mano.) Deja, hombre, deja ver... Nada. Ni la más mínima huella... (Mirando ambas muñecas.) La historia de nuestras vida. Enrique: en mi todo queda; en ti todo pasa (Heiremans, Moscas 52).

La acción "ocurre en un fundo, a 150 kilómetros de Santiago [circa, 1958]" (Heiremans, Moscas 7). Los protagonistas son Julián -mezcla entre "tulipán” y "magnolia apócrifa" (233)- y Enrique -“el de los pantalones de golf", "ese que apenas hablaba" (235)- . De complexión asténica -como los púberes de E. M. Forster-, los quinceañeros comparten más allá de lo que los regímenes domésticos y escolares permiten: “Julián le pegó [a Enrique] las paperas, la alfombrilla, la peste cristal" (Heiremans, Moscas 20). Entonces, también, intuyen que la ley que atemoriza a sus padres venidos a menos los privará del destino privilegiado de sus antepasados -la diplomacia, el sacerdocio o la Marina- . Siempre escapistas, antes del adiós, celebran "una fiesta veneciana", con góndolas prefabricadas y escenografía de cartón piedra. Eso sí, ya cumplida la mayoría de edad, a ellos, les toca "ajustar" la tierra, el cuerpo y el deseo. Acotaciones y diálogos dan pistas precisas: Enrique se emplea en una "compañía minera" y lo "mandaron al norte" -destinación: "Calama"-; despechado, Julián se casa con una señorita muy pía -¿Sepúlveda Leyton, Arizmendi?- y, con ingente pasivo sobre su espalda, permanece en el campo porque "no le queda sino este fundo", "la vida en Santiago es sumamente cara" y "aquí todavía puede tener sus comodidades" que le permiten "[v]ivir como antes" (Heiremans, Moscas 30).

"De ahí venía el miedo", diría el novelista Jorge Marchant Lazcano, de la inviabilidad del ayer. Porque, ¿cuáles son esas comodidades ya vedadas? La 
escritura de sus contemporáneos completa el cuadro: el patio de servicio, donde los niños con gracia de tulipán son polinizados por los hombrecitos toscos como abejorros, como en Niño de lluvia (1942) de Benjamín Subercaseaux; el retén comunal, donde el régimen de conscripción es la iniciación de la sodomía, en Fantasmas literarios (2005) de Hernán Valdés; o el hombrecito, casi siempre "muchachote lozano y muy moreno" dispuesto a socorrer al delicado señorito, siguiendo Veraneo y otros cuentos (1955) de José Donoso. En ese cuadro, las pinceladas obscenas, las que podrían mancillar la lengua, se pueden cifrar entre citas y galicismos de dandi o mero diletante: "[e]n el colegio, yo agonizaba con Verlaine y Rimbaud" (Moscas 21).

Pero, lejos del fundo -"un edificio medio derruido" (Heiremans, Moscas 9)-, y "en la época actual [ca. 1958]" (Heiremans, Moscas 7), los bríos de la reforma alteran el sentido de la teatralidad. En Calama -donde supervisa obras- o Santiago -donde entrega reportes-, Enrique sabe que la pose de dandi resulta obsoleta. El ensayista Óscar Contardo, por ejemplo, recolectando testimonios de hombres homosexuales contemporáneos a los personajes de Heiremans, consigue relatos que dan cuenta de las nuevas economías del deseo que se desarrolla en la urbe -esa urbe lejana al fundo de Julián-: “en el auto de mi mamá íbamos a patinar por calle Huérfanos. Recogíamos gente joven y la llevábamos arriba a Las Condes, donde no había nada. Todo pasaba en el auto o al aire libre. También íbamos a la plaza Pedro de Valdivia. Allí iban conscriptos. Les pagábamos con ropa" (151).

En la excitación de la noche citadina, la hoja del sacapuntas del pupilo cede su lugar a la navaja del "mostacero"; el pantaloncito de golf al "terciopelo derrotado" de "hombres luciérnagas"; la sangre, la alfombrilla y las paperas -no mucho después-, al virus y el sarcoma. El juego letal que trama Julián bien parece ser el ensayo fallido de su ingreso en un mundo donde el intercambio afectivo y sexual entre compañeros traería consecuencias tanto más crudas que las paperas:

Al principio los sodomitas, creyendo que a cada instante les caería la teja policial, se mostraron cautos. Pero ligerito se soltaron las trenzas y sacaron sus descomunales patas del plato y se lanzaron demostrando que la libertad que exigen, no es más que libertinaje. Entre otras cosas, los homosexuales quieren que se legisle para que puedan casarse y hacer las mil y una sin persecución policial. La que se armaría. Con razón un viejo propuso rociarlos con parafina y tirarles un fósforo encendido (Gamboa cit. en Robles, párr. 10). 
Nada de tulipanes ni magnolias: "yeguas", "mariposones", "colipatos". A lo sumo, claveles plásticos "color sangre", como concedería Andrés Pérez para aludir con la metáfora a la contigüidad material entre la artificialidad de la pose travesti y los fluidos corporales que, por dolor y goce, al final de la noche las tiñen. ¿Cómo querría Julián dejar el fundo?, ¿cómo querría Enrique renunciar a la ciudad? Ambas preguntas son anverso y reverso de la sensación de agorafobia - pavor súbito a los espacios desconocidos-que suscita en los sujetos queer la recomposición de un nuevo paisaje del deseo: los tajos de Enrique y Julián enseñan, a los entendidos, esa "enorme cicatriz luminosa". En suma, nuestra interpretación es más metonímica que simbólica. En lugar de avanzar hacia otras dimensiones (extraterrenas u oníricas), optamos por ver fragmentos de un léxico que, en secreto, intenta decir aquí y ahora todo aquello que permanece proscrito.

Literalmente, es cuestión de palabras: dos varones adolescentes -Enrique y Julián- aprenden a decir su afección con el escueto léxico que decantan bajo el alero de sus periféricas bibliotecas rurales -antes que citar versos de Rimbaud y Verlaine, citan los rumores que los biógrafos mantienen en entredicho-. La crisis del latifundio sobre el que se yerguen esas bibliotecas los obliga a buscar nuevos amparos en una ciudad donde los galicismos esnob se desvanecen en medio de una jerga que oscila entre el coa y el improperio ("colas", "mostaceros", "teresos"). De ahí que, en la lógica de nuestra argumentación, señalemos que Moscas sobre el mármol otorga las claves contextuales que explican el conflicto que presenciaremos en Arpeggione: cuando las palabras caducan y el afecto se aferra a las maromas de un instrumento extraviado.

\section{HÍBRIDOS CONDENADOS A LA DESAPARICIÓN}

Arpeggione es la tercera parte de Buenaventura, una trilogía de obras breves compuestas por diálogos de pareja mujer-hombre en espacios cerrados, explorando la "buenaventura" a la que no logran acceder más que fragmentariamente 7 . En Arpeggione, Lorenzo, un chelista profesional famoso, contrata temporalmente a Rosa, una pianista amateur desconocida,

\footnotetext{
de 1962.

Las otras dos obras de la trilogía son El año repetido y El mar en la muralla, ambas
} 
para que lo ayude a ensayar la sonata en la menor “Arpeggione”, D. 821, de Franz Schubert, en su versión para chelo y piano. La contratación de Rosa es una medida desesperada por parte de Lorenzo, pues se acerca una gira y su acompañante regular se ha ido de viaje.

Heiremans refuerza la jerarquía entre Lorenzo y Rosa mediante la dinámica que presentan los dos instrumentos en la obra de Schubert. En la obra de Heiremans, Lorenzo le dice a Rosa que "[1]a parte del piano casi no cuenta" y que "[e]l piano está al servicio del otro instrumento" (Heiremans, "Arpeggione" 379). Y, más tarde, que "[e]l acompañante tiene que estar al servicio del artista" (Heiremans, "Arpeggione" 388). En la sonata en la menor, el material musical está claramente jerarquizado, con el chelo presentando lo importante y el piano realizando un rol decididamente secundario de apoyo. En palabras del crítico musical Leo Black, esta sonata "no presenta mucho en cuanto a diálogo[,] el héroe o instrumento solista frecuentemente parece estar solo, y el 'acompañante' solo puede intentar apoyar de la mejor manera que puede, lo que significa que solo hay unos pocos pasajes en que el piano tiene el papel principal" $(7)^{8}$.

La ausencia del acompañante regular, cuyo nombre nunca se menciona, es el eje dramático de la obra. La relación entre el chelista y su acompañante y la crisis que provoca la ausencia de este último motivan buena parte del diálogo entre Rosa y Lorenzo. La función dramatúrgica de Rosa, mujer con nombre de flor, es relevar todas las maneras en que ella no es capaz de reemplazar al acompañante ausente. Esta imposibilidad no radica en las limitaciones técnico-musicales de Rosa, aunque el texto las evidencia de manera despectiva y misógina. Rosa no puede reemplazar al pianista porque la relación entre el chelista y su acompañante ausente va más allá de lo meramente profesional.

Este asunto innombrable es tratado por Heiremans mediante ambigüedades y ocultamientos característicos de una epistemología del closet. El acompañante ausente no solo es un personaje sin nombre, sino que durante gran parte de la obra Heiremans realiza un esfuerzo escritural para evitar especificar el sexo del pianista ausente. La obra presenta una fascinación morbosa por lo híbrido y la imposibilidad de que un híbrido procree, así como un interés en espacios homosociales cargados de intimidad y complementariedad.

8 Las fuentes referidas en inglés que se citan en español, para realizar precisiones léxicas que de otro modo se extraviarían, han sido siempre traducidas por los autores. 
Durante la obra, los personajes ensayan, en orden, los tres movimientos de la sonata en la menor de Schubert. Sin embargo, Heiremans no busca una verosimilitud completa con los detalles musicales de la partitura. Cuando en el texto dramático hay referencias a compases específicos o a notas alteradas ("bemoles") se producen imprecisiones, y el tercer movimiento es referido, múltiples veces, con un nombre incorrecto (Allegro en vez de Allegretto). De todas formas, es indudable que Heiremans comprendía a cabalidad la experiencia íntima que requiere la interpretación de música de cámara de la primera mitad del siglo XIX. En el diálogo de Arpeggione se explicita la intimidad y complementariedad que pide la interpretación de una sonata como esta:

LORENZO. Alguien que me ayude a repasar la partitura. Mi acompañante, como usted sabe, se le ocurrió irse de viaje.

ROSA. Sí, fue lo que el señor Landa me dijo. Es una lástima, ¿no? Yo siempre he pensado, al escucharlos, quiero decir, que ustedes se complementan tanto (Heiremans, “Arpeggione” 380).

La música de cámara de Schubert, en particular, es marcadamente intimista9 Esto se debe a que Schubert compuso música de cámara para tocarla él mismo junto a su grupo cercano de amigos, todos hombres y la mayoría no músicos profesionales (Chusid 174). De hecho, durante su vida, la mayoría de las interpretaciones de sus obras fueron hechas por su círculo cercano. Esto hace que la música de cámara de Schubert sea una música "de intérpretes", una música para ser hecha por amigos y entre amigos. Así, la música de cámara de Schubert habilitaba un espacio homosocial íntimo entre hombres. Entre varios de ellos estas relaciones también fueron afectivas (Solomon).

En la obra de Heiremans es evidente que el vínculo de Lorenzo y su acompañante ausente también excede lo musical. La ruptura entre ellos no solo tiene implicancias profesionales, sino personales. "Un acompañante

\footnotetext{
A pesar de haber fallecido tempranamente a los 31 años, Schubert fue un compositor muy prolífico. En una carrera que duró solo 18 años compuso casi mil obras, cubriendo prácticamente todas las agrupaciones utilizadas a comienzos del siglo XIX (desde obras para piano solo hasta óperas). Donde más se destaca, sin duda, es en la música de cámara. Es decir, música para ensambles pequeños (dúos, tríos, cuartetos, quintetos). Para efectos de esta discusión, incluimos las canciones, las más de 600 que compuso, dentro de la música de cámara.
} 
forma parte de la vida de un músico" (Heiremans, "Arpeggione” 388), dice Lorenzo. La ausencia de su acompañante lo lleva a sentirse amenazado, lo que lo atribula. Lorenzo desearía "ser fuerte" y "no depender de nadie". Quisiera "aprender que uno es solo" (Heiremans, "Arpeggione" 385). Se entiende que Lorenzo y su acompañante oculto, innombrable, han desarrollado una relación estrecha y afiatada y que la gira no puede continuar sin él.

Aquí es importante observar que, durante la mayoría de la obra, Heiremans mantiene en secreto el sexo del acompañante ausente de Lorenzo. Casi hasta el fin, tanto Lorenzo como Rosa se refieren al pianista ausente como "acompañante". No se especifica si es hombre o mujer, lo que llama la atención dada las contorsiones que requiere en los diálogos. Al tratarse de un recurso repetido, descartamos que la indefinición del sexo del acompañante sea por descuido o casualidad. Heiremans era políglota, trabajó como traductor y pasó largas temporadas en países en que se habla otra lengua. Se trata de una ambigüedad consciente. Como muestra el diálogo siguiente, ocultar el género es un trabajo:

ROSA. [...] ¿Ha tenido alguna noticia?

LORENZO. ¿De quién?

ROSA. De su acompañante.

LORENZO. No.

ROSA. El señor Landa tampoco ha sabido nada.

LORENZO. ¿Quién se lo dijo?

ROSA. Él mismo, el señor Landa. Le pregunté esta mañana. Me dijo que no había tenido ninguna noticia.

LORENZO. No, no ha tenido.

ROSA. Ojalá vuelva. Quiero decir. ojalá vuelva para que puedan ensayar juntos. Antes de la gira, quiero decir (Heiremans, "Arpeggione" 382).

ROSA. A lo mejor... mañana... tiene noticias.

LORENZO. ¿De quién?

ROSA. De su acompañante (Heiremans, “Arpeggione” 384-85).

También es muy significativa la elección de la sonata en la menor, "Arpeggione". Schubert compuso esta sonata para un instrumento inusual, un híbrido entre guitarra y violonchelo, que había sido inventado en 1823, solo un año antes de la composición de la sonata. Como una guitarra, este instrumento contaba con trastes en el diapasón y con seis cuerdas afinadas como 
una guitarra. Como un chelo, se tocaba con un arco, con el instrumento entre las piernas. Durante la década de 1820, el instrumento se conocía no como arpeggione, sino como Bogen-Guitarre (guitarra arco), Guitarre-Violoncell o guitare d'amour. El instrumento tuvo una corta vida; en el lapso de una década cayó en desuso, y la única obra importante compuesta para él fue, precisamente, la sonata de Schubert.

La sonata en la menor no tuvo mayor repercusión durante la vida de Schubert. Fue publicada póstumamente, en 1871, y es en esa edición que aparece por primera vez el nombre "Arpeggione" para referirse al instrumento (Jones 76). Dado que en ese momento la guitarra-violonchelo o arpeggione ya estaba en desuso, el editor decidió incorporar una transcripción para violonchelo. Esta versión para chelo es la más conocida y la que se interpreta con cierta regularidad. Sin duda, es esta versión la que escuchó Heiremans a mediados del siglo XX, y es esta versión la que ensayan los personajes de su obra.

El texto de Heiremans hace evidente que la particular historia "trágica" del instrumento mismo es clave para la obra. Lorenzo se toma el tiempo de contarle a Rosa el devenir del arpeggione. Lo describe como "una especie de guitarra, pero con algo de cello". (382). Para Rosa, es precisamente esta cualidad híbrida la que explica su desaparición:

ROSA. Es lógico que haya desaparecido, ¿no le parece?

LORENZO. ¿Por qué?

ROSA. Porque como decía mi papá, nada de lo que es híbrido dura (Heiremans, “Arpeggione" 382).

Rosa tiene una relación profundamente ambivalente con la cualidad híbrida del instrumento. Por una parte, su extrañeza la conmueve. "Parece algo mitológico" (Heiremans, "Arpeggione" 384), dice. Pero por otra le causa risa. Es mejor no mencionar el instrumento, porque su nombre le parece ridículo y le produce una risa irracional.

El hecho de que el arpeggione cayera en desuso se alinea con una preocupación recurrente en la obra sobre lo que perdura y lo que desaparece y propone una conexión temática con los híbridos de jardín, como las rosas, que no se pueden reproducir por sí mismos. En este caso, el híbrido, condenado a desaparecer, pareciera encontrar en el arte un poder partenogenético. Rosa, refiriéndose a Lorenzo, dice: "Se me ocurre todopoderoso. Como cuando mi padre se sentaba al piano. Solo con su instrumento, alejado, bastándose a sí mismo. Procreando en sí..." (Heiremans, "Arpeggione" 381). En un 
momento, Rosa le habla directamente al arpeggione: "Guitarra de amor, llévame... Arpeggione, llévame" (Heiremans, "Arpeggione" 385). En el contexto de desear que Lorenzo se la lleve de gira como su acompañante, es evidente que el instrumento opera como metonimia de Lorenzo mismo. Lorenzo es el instrumento híbrido, nombrado con palabras risibles, condenado a no nombrarse y desaparecer.

El fiato entre Lorenzo y Rosa recién aparece en el tercer ensayo. Entonces él reconoce, por primera vez, que le gustó cómo tocaron un trozo. Y el motivo es que "nos estamos acostumbrando a tocar juntos" (Heiremans, "Arpeggione" 386). En uno de los momentos de mayor alegría de los personajes, cuando la sonata empieza a sonar satisfactoriamente, Rosa explica que esto se debe a que ella descubrió que su destino es "acompañar":

LORENZO. No tengo que retroceder ahora. No puedo seguir esperando. Llevaré a cabo la gira tal cual la había previsto. Si es necesario, como le dije a Landa esta mañana, me llevaré a esta mujer para que me acompañe (Heiremans, “Arpeggione" 383).

Por un momento, Lorenzo tiene la ilusión de que podría construir una vida junto a esta mujer. Al nombrarla, el género se explicita, siendo doblemente innecesario cuando vemos al personaje en escena. Hay aquí una idealización de la presencia femenina subordinada a un hombre con una vida secreta, innombrable; el sacrificio de una mujer que voluntariamente decide acompañar a un hombre protagónico, distante, con una vida distinta e inalcanzable dentro del bosque. Rosa cree en la sugerencia de Lorenzo y se prepara para el viaje, solo para enterarse del regreso del acompañante que, aunque siga sin nombrarse, por una sola vez, la última vez que se menciona, se desambigua y es "un" acompañante.

LORENZO. Ah sí. había olvidado decirle. Hasta recibí una carta de mi acompañante esta mañana. ¿Ve cómo el mundo está de acuerdo? Estaba muy molesto, porque no sabía cómo cumplir mis contratos. Después de todo estamos acostumbrados a tocar juntos. Un acompañante forma parte de la vida de un músico, como su instrumento, como sus horas de ensayo, como su personalidad. El acompañante tiene que estar al servicio del artista, ¿No le parece...? (Heiremans, "Arpeggione” 388). 
En el nivel superficial, el que lleva la acción es Lorenzo, es él quien quiere algo de Rosa (ensayar), es él quien sufre el tormento de haber perdido a su acompañante y Rosa, al principio, se limita a ofrecerle un contraste con su franqueza y apertura. Más adelante, cuando, tras recibir la oferta de acompañar a Lorenzo en su gira, Rosa llega ilusionada y recibe en escena la noticia del regreso, Lorenzo la abandona abruptamente. En este giro se completa la restauración de Lorenzo a un punto anterior al inicio de la obra y el cambio en Rosa con la destrucción de su ilusión. Rosa adquiere protagonismo mediante su transformación. Se trata de una obra de cámara armada sobre una obra de cámara, que ni siquiera se interpreta ante público. Intimidad sobre intimidad, secreto sobre secreto.

Arpeggione tematiza la imposibilidad de nombrar el deseo y la obligación de encerrarse y ocultarse de los demás:

ROSA. No sé cómo llegar hasta él. Me gustaría encontrar una palabra, algo, que fuese como una llave. Que yo dijera... no sé, cualquier cosa y que él se abriera como... como cuando una abre la puerta de una pieza y adentro todo está lleno de sol... Eso es (Heiremans, “Arpeggione" 380).

Al intento de Rosa de penetrar los secretos de Lorenzo, él solo puede responder con un encierro todavía más profundo:

LORENZO. [...] Tengo que vencer el miedo y volver a entrar en el bosque. Igual que antes. Tengo que recordar eso. Yo siempre fui solo, desde niño. Aun cuando había gente alrededor mío, siempre fui solo. Un artista es un hombre solo. Tiene que hacerse fuerte en esa soledad. Tengo que acordarme cómo antes entraba en ese bosque (Heiremans, "Arpeggione" 383).

Este par de llave y bosque está condenado al fracaso. A diferencia de un clóset o un cajón, no hay llave que pueda abrir un bosque. Rosa, cuando pequeña, no lograba seguir el paso de su padre en el bosque. El aislamiento de los personajes aumenta a medida que la interpretación musical conjunta pareciera acercarlos:

ROSA. Todavía no logro encontrar esa palabra.

LORENZO. En los bosques nunca hay eco. 
ROSA. Como una llave.

LORENZO. El mundo es como un bosque.

ROSA. Como algo que abriera.

LORENZO. Nadie responde.

ROSA. Tal vez si la encontrara, él pensaría...

LORENZO. Y yo aprendía a no depender de nadie.

ROSA. Llévame.

LORENZO. Y ser así, solo.

ROSA. ¡Llévame! No he tenido a nadie desde...

LORENZO. Desde que era niño, en ese bosque, lo aprendí. [...] Bajo los árboles aprendí a ser solo, y fuerte.

ROSA. Si al menos me escuchara.

LORENZO. ¿Por qué habría de sentirme amenazado ahora?

ROSA. ¿Cómo hacérselo saber, Buenaventura?

LORENZO. ¿Por qué habría de sentirme amenazado porque alguien se va? [...] Lo decidí hace tiempo. Debo volver al bosque, igual que antes. Buscar una palabra dura. igual que antes. Gritarla, igual... igual que antes.

ROSA. (Casi con un grito.) Guitarra de amor, llévame.

LORENZO. Aprender que uno es solo.

ROSA. (Riendo suavemente.) Arpeggione, llévame.

Lorenzo. Fuerte.

ROSA. Dame la llave (Heiremans, “Arpeggione” 385).

Esta tensión entre la intimidad deseada y el temor a revelarse, a quedar al descubierto en la fragilidad y soledad, en la cualidad innombrable que provoca las risas del resto, alimenta el ánimo fluctuante en los personajes que recorre Arpeggione.

Por último, la elección de Schubert como compositor es en sí significativa para una lectura queer. Esto, dado que la masculinidad de Schubert ha sido fuente de debate desde la primera mitad del siglo XIX. Ya su contemporáneo, el compositor Robert Schumann, comparaba negativamente a Schubert con el parangón de la masculinidad romántica, Ludwig van Beethoven:

En comparación con Beethoven, Schubert es un personaje más femenino. Es mucho más locuaz, blando, amplio. Comparado con Beethoven, es un niño, jugando feliz entre los gigantes [...] es más femenino que masculino, ya que ruega y persuade, mientras que el hombre ordena" (citado en Brett 155). 
Durante el siglo XX, algunos críticos caracterizaron su música con adjetivos comúnmente usados para describir a hombres homosexuales ("nervioso", "patético"), mientras que otros intentaron limpiar estas sugerencias celebrando la robustez de sus obras y sus interacciones con mujeres. El debate escaló considerablemente en 1989, con la publicación de un artículo del musicólogo Maynard Solomon en que se sugiere, en base a evidencia documental, que Schubert participó activamente de una comunidad vienesa homosexual. La reacción de la comunidad musicológica internacional fue intensa, convirtiendo el artículo de Solomon en una de las cause célèbres de la disciplina. Posteriormente, Kristina Muxfeldt relevó el hecho de que Schubert compuso canciones basadas en textos del poeta homosexual August von Platen, textos marcadamente homoeróticos. Muxfeldt convincentemente demuestra que la musicalización que Schubert hizo de estos poemas contiene una intensidad armónica inusual dentro de su repertorio de más de 600 canciones (480-527).

Entrado el siglo XXI, la sexualidad de Schubert sigue siendo asunto de debate. Gingerich concluye un detallado estudio sobre el compositor diciendo que "la homosexualidad de Schubert se mantiene como un asunto especulativo, no probado y probablemente imposible de probar" (86). Mientras que el crítico Alex Ross argumenta que la "heterosexualidad" de Schubert es también especulativa, ya que no existe evidencia tampoco de relaciones afectivas con mujeres (133).

En cualquier caso, es importante reconocer que Schubert y su música han sido un referente esencial para hombres gay alrededor del mundo. El destacado musicólogo inglés Philip Brett, fundador de lo que hoy conocemos como musicología gay y lésbica, escribe que para él Schubert fue un referente en el proceso de construcción de su identidad sexual, desde mucho antes que Solomon escribiese sobre la homosexualidad del compositor. Brett escribe que "en última instancia, es gracias a un Schubert homosexual que yo debo mi salida académica del clóset y también la dedicación a relevar el problema de la sexualidad en la música" (168). Esto, debido a que Schubert "encontró un refugio en la música y el arte, sufrió profundas depresiones y tuvo problemas para expresar la rabia, todas señas evidentes de una sensación de exclusión social en la era moderna en occidente" (ibid.). Esta experiencia no es única, sino que "les sirvió a generaciones de homosexuales en el armario en búsqueda de apoyo en el pasado" (Brett 169). Para Brett, la certeza de la homosexualidad de Schubert no es condición sine qua non para justificar el rol del compositor como referente para hombres gay del siglo XX: "Es claro que Schubert asumió actitudes antireligiosas, pro-Clásicas, antiautoritarias y 
prosensualistas del tipo que los homosexuales frecuentemente han tendido a adoptar" $(169)^{10}$.

\section{LEJOS DE CHILE}

Dijimos al inicio que Luis Alberto Heiremans fue, considerando lo breve de su vida, un autor prolífico. Fue, además, un autor estimado por sus pares, que se movió por igual entre los teatros universitarios de la Universidad de Chile y Universidad Católica y el teatro independiente, donde obtuvo gran éxito con ¡Esta señorita Trini! (1958), considerada como la primera comedia musical chilena. Es interesante que las dos obras que acabamos de analizar fueran estrenadas lejos de Chile en vida del autor. Moscas sobre el mármol se publicó en Chile en 1958, pero su estreno mundial fue en 1961, en Münster, Alemania, durante uno de los muchos viajes de Heiremans a Europa. Buenaventura se escribió en París y se estrenó en 1962 en el Teatro Municipal de Friburgo, bajo la dirección de Klaus Leininger. Al parecer, Arpeggione, tercera parte de la trilogía, la habría añadido el autor a pedido del director en Alemania.

Como ya mencionamos, Luis Alberto Heiremans se movía con comodidad en varios idiomas y el sistema teatral alemán no le resultó ajeno. Es perfectamente posible que solo estuviera probando obras de bajo presupuesto con amigos mientras reservaba los proyectos más grandiosos para sus últimos años en Chile. Tal como diría Kosofsky Sedgwick, es inoficioso buscar una declaración explícita sobre las intenciones expresivas, si expresaron lo prohibido en su tiempo (36). Las obras que hemos discutido tematizan el secreto más que la revelación. Es verdad que Heiremans profesaba el vínculo indestructible entre creador y obra, pero también que alababa el "soplo pequeño, aquel que afecta a todos en forma mínima" (Heiremans, "La creación” 199). No podemos esperar una revelación suya sobre estrenar fuera de Chile. Es posible pensar que el medio teatral europeo, más tolerante, haya permitido a Heiremans explorar estas insinuaciones del deseo homoerótico. También es posible que solo haya sido la liberación temporal de Chile, donde hasta

10 Charles Fisk describe una situación similar en su capítulo, "Endangered Tenderness: Schubert, Chopin, and Schumann", perteneciente al libro The Oxford Handbook of Music and Queerness, editado por Fred Everett Maus and Sheila Whiteley. 
la representación sumamente pudorosa de un prostíbulo podía ser causa de escándalo en un estreno teatral, como le ocurrió al propio Heiremans con Versos de ciego. El propio Heiremans dejó constancia de su admiración por la crítica extranjera, que le parecía daba más espacio: "La crítica europea tiene un enfoque más tranquilo, detallado y exhaustivo. Es más provechosa que la chilena, aun cuando critica en forma desfavorable" (cit. en Véjar 2).

Más allá de las razones biográficas de Heiremans, lo que sí depende de nosotros, espectadores y lectores, es interpelar a nuestro propio sistema teatral: el dramaturgo partió pronto; nosotros, que lo sobrevivimos, en cambio, no supimos qué hacer con ni con la lengua de los adolescentes afectados (Moscas sobre el mármol) ni con la indeterminación que une a los músicos (Arpeggione). Sintomáticamente, padecimos un "pánico homosexual" (Kosofsky Sedgwick 240-280). Fuimos nosotros los que no supimos como leer, en primera persona -como manda el género dramático-, en una sala de clases o un escenario teatral, una lengua rara, queer: en la lengua de Heiremans, los sustantivos que mientan los deseos esquivan las líneas "rectas" del parentesco heterosexual (Moscas sobre el mármol); en ella, las desinencias de género permanecen siempre suspendidas, pudiendo significar lo femenino, masculino o lo neutro (Arpeggione).

En este contexto, incluir siquiera la posibilidad de romper la interpretación heteronormativa que se ha hecho de la obra de Luis Alberto Heiremans debería alimentar nuevas posibilidades estéticas para su escenificación, pero también solucionar algunos aspectos que, cuando nos cerramos a esta interpretación, se vuelven confusos. La homofobia crítica e historiográfica produce relatos confusos y por momentos incoherentes (Party 50). El portal Memoria Chilena describe Arpeggione así: "Trata de dos músicos, Lorenzo y Rosa, quienes divagan mientras ensayan la obra musical" (párr. 6). La obra trata el tema homoerótico con un andamiaje de alusiones y sugerencias, pero se trata de alusiones obvias a menos que nos esforcemos en ignorarlas. El esfuerzo de negar esta interpretación posible convierte a lo que los personajes tratan de decir sin revelar en una pura divagación.

El teatro de Heiremans estableció relaciones ricas y complejas con la idea de chilenidad y, sumado a ello, con el teatro realista, que fue uno de los motores de desarrollo de los escenarios universitarios chilenos. Sus obras contienen maneras originales de abordar el landscape play (Duffy 30). Este trabajo de tensión con la matriz dominante de realismo/naturalismo recuerda que la relación teatral con lo real no es nunca simple ni directa (straight) y permite explorar dobleces, misterios y espacios para la aparición de lo no 
normativo (Duffy 32). El resto de su obra también se ilumina si aceptamos la hipótesis de que es posible que estas piezas tematicen el sufrimiento de no poder explicitar el deseo homoerótico. Los dos hombres acróbatas, que le parecen a la Emperatriz la pareja más perfecta en El tony chico (339), dejan de parecer solo ángeles. Su coordinación ajustada, sus trajes ajustados, su manera de sentarse aparte y no participar del coqueteo con mujeres los vuelve, por fin, hombres, una pareja de hombres. O la meditación metafísica del Teniente Bruna, que en vez de espejo se afeita mirándose en el rostro de un ordenanza joven en El abanderado (332), es también, por fin, una escena cargada de erotismo a la vez uniformado y con poca ropa; la duplicidad de Cornelio y Cornelia, los únicos inocentes de esa misma obra, y muchos otros episodios se transforman si permitimos esa línea de interpretación.

Invisibilizar la homosexualidad es una forma de ejercer una "homofobia crítica", en una actitud que encerraría la intención manifiesta o inconsciente de ocultar aspectos "indecorosos" o narrativamente incómodos de la vida de los artistas: "En un contexto en que una persona es censurada, reprimida o discriminada por solo dar la impresión de no ser heterosexual, es difícil imaginar que su labor profesional no esté marcada por esta experiencia social" (Party 47). En nombre de un supuesto respeto por la memoria de un autor fallecido, perpetuamos la violencia a comunidades marginadas y solo ganamos a cambio la incomprensión. Deberíamos, mejor, actuar como dicen que hacía el propio Heiremans:

En él, todo siempre se ordenaba en una lógica tierna, que surge al no aplicar juicios al dolor de los hombres, porque Tito no juzgaba, porque sentía demasiada compasión para hacerlo, y porque en la más profunda interioridad de su inteligencia, sabía que la justicia de los hombres es injusta, porque la vence el tiempo y la relatividad de las cosas, y porque en el mal y en el error, los hombres nos hacemos hermanos (Wolff 79).

La devoción cristiana ha sido vista como la matriz de la teatralidad y la simbología del trabajo de Heiremans. Aunque a primera vista podría parecer reñida con la exploración artística del deseo homosexual, sabemos que ambas pueden trenzarse de forma profunda, tal como afirma Gibson sobre la poesía de Federico García Lorca, la que "no existiría si no fuera por su condición de marginado sexual, por su identificación, profundamente cristiana, con todos los que sufren, con todos los que se sienten excluidos o rechazados" (379). 
Discutiendo lo que llama la "empresa cartográfica" de las universidades chilenas en el proceso de modernización, Opazo afirma que un aspecto clave fue el quehacer de sus pupilos aventajados; hijos de una élite recientemente migrada, en muchos casos no hispanoparlante (348). O, aristócratas que, venidos a menos, deben abrazar profesiones liberales. Aquí, la disquisición de Heiremans resulta capital: la incomodidad de los pupilos ante "este mundo que está descoyuntado" y el proceso incómodo de modernización genera reacciones de variado alcance. La más evidente tiene lugar ante la reforma universitaria de 1967: piénsese, sin ir más lejos, en Nos tomamos la universidad (1969) de Sergio Vodanovic. La transformación de los espacios que el Chile agrícola permitió para el desarrollo de los afectos queer trajo también otras formas de resistencia que han sido menos visibilizadas por la historiografía literaria y teatral chilena: la transnacionalización y la cosmopolitización forzada. Así podríamos entender los exilios y voluntarios destierros de la nueva generación de caballeros: Enrique, en Moscas sobre el mármol, y Jorge Díaz, Heiremans, Luis Oyarzún, Mauricio Wacquez o, peor aún, la "inmolación" de Rafael Elizalde.

Moscas sobre el mármol y Arpeggione presentan dos variantes del mismo proceso de transformación de las posibilidades de una vida queer en un estado con afán higiénico de modernidad: en la una, la imposibilidad del refugio en el campo; en la otra, la soledad de la vida errante. Si bien se ha estudiado la cualidad viajera, fugada, de las redes queer que sostuvieron las vidas de intelectuales internacionales nacidos en el sur global (Cabello 147) y la repercusión que tuvo este sistema en el desarrollo de la literatura latinoamericana, el teatro chileno se sigue estudiando desde una perspectiva nacional, atendiendo al proyecto que se dio a sí mismo.

Las propias obras cuentan, a la vez, la delimitación y reforzamiento del territorio nacional, historias de giras, refugios en lugares más tolerantes, abandonos y confusiones. Sabemos del estímulo intelectual que encontraron en Europa y Estados Unidos muchos artistas de los teatros universitarios entre su fundación y su tiempo hegemónico antes del golpe de Estado de 1973. Sabemos que ese programa de viaje permitía reforzar el espíritu moderno de estas instituciones, su deseo de "estar al día", mientras desarrollaban un teatro de alcance nacional. Pero sabemos menos de las afinidades humanas, los deseos y las libertades que se encontraron fuera de Chile, aunque no fueran menos importantes. La red de amistades y otros afectos que permitió la supervivencia de un arte tan delicado está todavía esperando que la leamos, que permitamos aflorar la intimidad que en su tiempo se prohibió, si nos atrevemos a nombrarla. 


\section{BIBLIOGRAFÍA}

Barnes, Julian. El loro de Flaubert. Barcelona, Anagrama, 2015.

Black, Leo. “Schubert's Ugly Duckling.” The Musical Times 138, 1857 (1997), pp. 4-11.

Brett, Philip. "Piano Four-Hands: Schubert and the Performance of Gay Male Desire." Nineteenth-Century Music 21, $N^{\circ} 2$, 1997, pp. 149-76.

"Buenaventura". Memoria Chilena (web, visitado el 27 de octubre de 2021, disponible en: http://www.memoriachilena.gob.cl/602/w3-article-95754.html

Cabello Hutt, Claudia. "Redes Queer: Escritoras, Artistas y Meces en la primera mitad del siglo XX”. Cuadernos de Literatura 21, N42, 2017, pp. 145-160.

Cajiao Salas, Teresa. Temas y simbolos en la obra de Luis Alberto Heiremans. Santiago, Fundación Luis Alberto Heiremans, 1970.

Chusid, Martin. "Schubert's chamber music: before and after Beethoven". The Cambridge Companion to Schubert. Christopher H. Gibbs (ed.), Cambridge, University Press, 1997, pp. 174-192.

Contardo, Óscar. Raro. Una historia gay de Chile. Santiago, Planeta, 2011.

Duffy, Clare. Applying Queer Theory about Time and Place to Playwriting. Tesis doctoral. University of Glasgow, 2012.

Edwards Bello, Joaquín. Criollos en París. Santiago, Quimantú, 1973.

Fernández, Teodosio. "El drama chileno en torno a 1960: el 'realismo psicológico"”. Anales de literatura hispanoamericana 6, 1977, pp. 109-124.

Fisk, Charles. "Endangered Tenderness: Schubert, Chopin, and Schumann". The Oxford Handbook of Music and Queerness. Fred Everett Maus y Sheila Whiteley (eds.), Oxford, Oxford University Press, 2019.

GiBson, IAn. Lorca y el mundo gay: "caballo azul de mi locura”. Barcelona, Planeta, 2009.

GingERICH, JoHn M. "“Those of us who found our love in art': The second-generation romanticism of the Schubert-Schober Circle, 1820-1825". Franz Schubert and his world. Christopher H. Gibbs y Morten Solvik (eds.), Nueva Jersey, Princeton University Press, 2014, pp. 67-113.

Gorc, Cedomil. La novela chilena. Los mitos degradados. Santiago, Editorial Universitaria, 1968.

Grass, Milena, et Al. "Theatre History vs. Theatre Canon. The Chilean Case". The Methuen Drama Handbook of Theatre History and Historiography. Claire Cochrane y Jo Robinson (eds.), Londres, Bloomsbury Publishing, 2019, pp. 79-89.

Guattari, Félix y Gilles Deleuze. Kafka, por una literatura menor. Ciudad de México, Era, 1999.

Heiremans, Luis Alberto. “Arpeggione”. Teatro completo de Luis Alberto Heiremans. Norma Alcamán Riffo (ed.), Santiago, RIL Editores, 2002, pp. 379-90.

"Buenaventura". Teatro completo de Luis Alberto Heiremans. Norma Alcamán Riffo (ed.), Santiago, RIL Editores, 2002. pp. 357-90.

"El abanderado". Teatro completo de Luis Alberto Heiremans. Norma Alcamán Riffo (ed.), Santiago, RIL Editores, 2002, pp. 327-56. 
"El tony chico". Teatro completo de Luis Alberto Heiremans. Norma Alcamán Riffo (ed.), Santiago, RIL Editores, 2002, pp. 391-426.

Moscas sobre el mármol. Santiago, Editorial del Nuevo Extremo, 1958.

"La creación personal y el trabajo en equipo en la dramaturgia actual". Atenea 131, No380-381, 1958, pp. 199-205.

Horan, Elizabeth. “Mistral, Gabriela”. Latin American Writers on Gay and Lesbian Themes: A Bio-Critical Sourcebook: A Bio-Critical Sourcebook. David William Foster (ed.), Wesport, Greenwood Press, 1994, pp. 221-235.

JoNES, Evan. "Motivic design and coherence in the first movement of Schubert's 'Arpeggione' sonata D. 821". Keys to the drama: Nine perspective on sonata forms. Gordon Sly (ed.), Farnham, Ashgate, 2009, pp. 73-99.

KALAWSKI, ANDRÉS. "Viuda universitaria, huacho moderno: trayectoria interpretativa y genética teatral de La Viuda de Apablaza". Anales de Literatura Chilena 30, 2018, pp. 113-128.

Kermode, Frank. "El control institucional de la interpretación". El canon literario. Madrid, Arco Libros, 1998, pp. 91-114.

Kosofsky Sedgwick, Eve. Epistemología del armario. Barcelona, Ediciones de la Tempestad, 1998.

Larraín, Hernán. “Versos de ciego: una obra discutida”. Revista Mensaje, 1961, pp. 11-30.

Muxfeldt, KRISTinA. "Schubert, Platen, and the Myth of Narcissus". Journal of the American Musicological Society 49, N³, 1996, 480-527.

Opazo, Cristián. "El lugar de las humanidades". Democracias incompletas: debates críticos en el Cono Sur. Fernando Blanco y Cristián Opazo (eds.), Santiago, Cuarto Propio, 2019, pp. 347-367.

Oyarzún, CARola. "Recurrencias a lo misterioso en la dramaturgia inicial de Luis Alberto

Heiremans". Heiremans. Carola Oyarzún L. y Cristián Opazo (eds.), Santiago, Ediciones Universidad Católica de Chile, 2012, pp. 15-42.

Oyarzún, Luis. Epistolario familiar. Thomas Harris E., Claudia Tapia Roi y Pedro Pablo Zegers (comp.), Santiago, LOM Ediciones, 2000.

Party, Daniel. "Homofobia y la Nueva Canción Chilena.” El Oído Pensante 7, N², 2019, pp. 42-63.

Sarlo, Beatriz. Una modernidad periférica. Buenos Aires 1920 y 1930. Buenos Aires, Ediciones Nueva Visión, 1988.

Solomon, Maynard. "Franz Schubert and the Peacocks of Benvenuto Cellini". NineteenthCentury Music 12, N³, 1989, pp. 193-206.

Robles, Víctor Hugo. "Las locas del 73 (primera protesta de la disidencia sexual en Chile". La voz de los que sobran (web), 22 de abril del 2020, visitado el 21 de noviembre de 2021, disponible en: https://lavozdelosquesobran.cl/las-locas-del-73-primera-protestade-la-disidencia-sexual-en-chile/

Ross, Alex. Listen to this. London, Picador Books, 2011. 
Thomas, EduARdo. "Función del juego en Buenaventura de Luis Alberto Heiremans". Heiremans. Carola Oyarzún L. y Cristián Opazo (eds.), Santiago, Ediciones Universidad Católica de Chile, 2012, pp. 107-141.

La poética teatral de Luis Alberto Heiremans. Santiago, Red Internacional del Libro, 1992.

VÉJAR, FrANCISCO. "El dandy y el artista”. Rocinante 83, 2005, p. 2.

Wolff, Egon. "En torno a Luis Alberto Heiremans". Apuntes de Teatro 99, 1989, pp. 78-86. 